REVES - Revista Relações Sociais, Vol. 04 N. 04 (2021)

https://periodicos.ufv.br/reves

elSSN: $2595-4490$

REVES-Revista Relaçoes Sociais (eISSN 2595-4490)

\title{
Inclusão da Pessoa com Deficiência nas Políticas Públicas de Emprego em Moçambique
}

Inclusion of Persons with Disabilities in Public Employment Policy in Mozambique

Domingos Carlos Batone

ORCID: https://orcid.org/0000-0002-3773-1451

Escola Superior de Economia e Gestão, Gabinete de Estudos e Projectos, Moçambique

E-mail: dcbatone@gmail.com

Article Info:

Article history: Received 2021-07-04

Accepted 2021-08-04

Available online 2021-08-04

doi: 10.18540/revesvl4iss4pp12931-01-16e

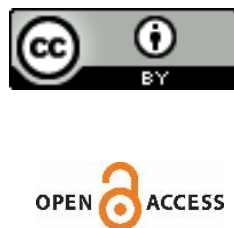

Resumo. O artigo discute a inclusão das Pessoas com Deficiência no mercado de trabalho moçambicano através de duas (2) dimensões das políticas públicas de emprego, nomeadamente, as passivas que fornecem suporte de renda para pessoas desempregadas por meio do seguro-desemprego e outros subsídios sociais, bem como as activas, destinadas a ajudar os deficientes desempregados a voltar ao trabalho com novas competências, por meio dos programas de treinamento e criação directa de emprego no sector público e privado. Embora ambas as abordagens tenham as suas valências, serão aplicadas na prática para verificar o nível de inclusão das PcD nas políticas públicas de emprego, identificar as alternativas e desafios para a sua Implementação. Recorrendo a uma metodologia mista, será operacionalizada a consulta bibliográfica, estatísticas do Quarto Censo Geral de 2017 e aplicadas entrevistas aos deficientes que integram a organização TV Surdo, vocacionada na defesa dos direitos das PcD. No entanto, a continuidade das práticas de descriminação e estigmatização limitam cada vez mais o seu acesso ao mercado de trabalho, demandando assim por medidas que promovam acções afirmativas para este grupo prioritário. O estudo chegou a conclusão de que, as políticas públicas de emprego em Moçambique são predominantemente passivas, no entanto, dos subsídios alocados desde 2018 até 2021 não sofreram nenhum incremento, apesar do comportamento da inflação demostrar o aumento do alto custo de vida. Assim, recomenda-se que as medidas passivas devem continuar, desde que sejam mais inclusivas e os empregadores precisarão de ser socializados a participar nos programas que revitalizem as políticas activas para este grupo vulnerável.

Palavras-chave: Inclusão. Pessoas com Deficiência. Políticas de Emprego. 
Abstract. The paper discusses the inclusion of people with disabilities in the mozambican labor market through two (2) dimensions of public employment policies, namely, the passive ones that provide income support for unemployed people through unemployment insurance and other social subsidies, as well as active ones, aimed at helping unemployed disabled people to return to work with new skills, through training programs and direct job creation in the public and private sectors. although both approaches have their strengths, they will be applied in practice to verify the level of inclusion of people with disabilities in public employment policies, identify alternatives and challenges for their implementation. Using a mixed methodology, bibliographic consultation will be carried out, along with statistics from the 2017 fourth general census and interviews will be applied to the disabled who are part of the TV Surdo organization, dedicated to defending the rights of people with disabilities. However, the continued practices of discrimination and stigmatization increasingly limit their access to the labor market, thus demanding measures that promote affirmative action for this priority group. The study reached the conclusion that public employment policies in Mozambique are predominantly passive, however, subsidies allocated from 2018 to 2021 did not increase, despite the behavior of inflation showing the increase in the high cost of living. thus, it is recommended that passive measures should continue as long as they are more inclusive and employers will need to be socialized to participate in programs that revitalize active policies for this vulnerable group.

Keywords: Inclusion. People with Disabilities. Employment Policy.

\section{Introdução}

O desenvolvimento de políticas públicas vem buscando abrir espaço, dar direitos e visibilidade para as Pessoas com Deficiências (PcDs) (SOUZA et al., 2017). No entanto, a continuidade das práticas de descriminação e estigmatização das PcD limitam cada vez mais o seu acesso ao mercado de trabalho, demandando assim por medidas que promovam ações afirmativas para este grupo prioritário. A Organização Mundial da Saúde (2011), refere que todos períodos históricos enfrentaram a questão moral e política de como melhor incluir e apoiar as pessoas com deficiência. Essa questão estará mais visível em função das mudanças demográficas das sociedades, pois, cada vez mais pessoas alcançam a idade avançada.

No âmbito das políticas de emprego, quatro tendências globais recentes aumentaram a importância dos empregos como uma preocupação política e renovaram o interesse na eficácia das políticas ativas. A primeira foi a crise financeira global de 2007-2008, que aumentou o desemprego em muitos países do mundo. Em segundo lugar, as crescentes pressões demográficas em algumas partes do mundo em desenvolvimento levaram às manchetes de uma "bombarelógio de empregos", com afirmações como a necessidade de 10 a 12 milhões de jovens entrando no mercado de trabalho anualmente na África e na região do Oriente Médio e Norte da África, que precisa criar 100 milhões de novos empregos até 2020. Terceiro, as altas taxas de desemprego juvenil, particularmente na região Oriente Médio e Norte da África, aumentaram os temores de agitação social e grandes fluxos de emigração (BANCO MUNDIAL, 2004; MOHAMMED, 2015; KELLY, 2016; MCKENZIE, 2018). 
Em Moçambique, a questão da deficiência é muito sensível tanto para as $\mathrm{PcD}$, assim como para a sociedade por ainda não estar preparada para lidar com esta situação (TRINDADE, 2020). Nesse sentido, é levantada a seguinte questão orientadora: Quão inclusivas são as políticas de emprego para às Pessoas com Deficiência em Moçambique?

Este artigo tem como objetivo geral analisar o nível de inclusão das Pessoas com Deficiência nas políticas de emprego moçambicanas. Em relação aos objetivos específicos, pretende-se: (i) Descrever o quadro legal e institucional sobre a Inclusão das Pessoas com Deficiência; e (iii) identificar as alternativas e desafios na Implementação das políticas ativas de emprego para às Pessoas com Deficiência.

A estrutura desde escrito obedece a seguinte ordem: a introdução, metodologia, revisão da literatura, resultados, conclusão e referências bibliográficas.

\section{Metodologia}

Esta pesquisa sustentou-se numa metodologia mista, pois, recorreu aos dados quantitativos produzidos pelo IV Recenseamento Geral da População e Habitação de 2017 para apurar os números das Pessoas com Deficiência em função dos tipos de deficiência, no entanto, foi usada também informação qualitativa produzida por meio das entrevistas efetuadas aos deficientes que integram a organização TV Surdo, vocacionada na defesa dos direitos das PcD e a consulta bibliográfica que suportou a revisão da literatura cujos temas abordados estavam associados a política de emprego e a Pessoa com Deficiência.

\section{Revisão da Literatura}

\subsection{Políticas Públicas}

Um dos grandes pesquisadores sobre políticas públicas (policy ou public policy) é Thomas Dye (2012), que vê elas como sendo tudo aquilo que o governo decide ou não fazer.

Assim sendo, as políticas públicas reconciliam interesses divergentes em relação à gestão de recursos escassos; estabelecem os incentivos para a cooperação e ação coletiva que seria irracional sem a influência do Governo; proíbem comportamentos moralmente sancionados; protegem as atividades de indivíduos e grupos e promovem atividades que são importantes para o Governo; e, finalmente, mas não menos importantes, as políticas públicas providenciam benefícios diretos para os cidadãos (THEODOULOU E CAHN, 2012).

Numa dimensão mais pragmática, as políticas públicas podem ser definidas como tentativas de regular situações que representam um problema público, em uma comunidade ou entre comunidades. Portanto, um problema é público quando afeta de alguma forma a distribuição de recursos entre os atores sociais. No caso da noção de comunidade, ela deve ser entendida em um sentido amplo, podendo ser uma coletividade política formada como um estado soberano, ou uma subcoletividade política dentro dessa coletividade maior (uma província, um município), ou mesmo uma grande organização (por exemplo, um hospital, uma universidade, etc.) (LEMIEUX, 1994).

Na perceção de Sitoe e Lumbela (2013), as Políticas Públicas envolvem as decisões que são tomadas pelo Governo ou Sector Público, num sentido mais geral, 
que de forma intencional e significativa afetam uma atividade ou sector da sociedade.

Portanto, nada impede que algumas políticas públicas nasçam do poder legislativo ou judicial, mas, o agente primário na elaboração destes instrumentos é o executivo (governo). Deste modo, as políticas públicas podem tomar a forma de lei, regulamentos, posturas, decretos e não é imperioso que sempre sejam chamadas de "Política X...". As políticas públicas podem ser estratificadas em função da sua hierarquia, podendo ser de abrangência mundial (exemplo, Objetivos de Desenvolvimento Sustentável-Agenda 2030), regionais, nacionais, transversais, sectoriais, provinciais, municipais e distritais. Conforme a tipologia de Theodor Lowi (1964), as políticas distributivas, envolvem as decisões tomadas pelo governo que desconsideram a questão dos recursos limitados, gerando impactos mais individuais do que universais, ao privilegiar certos grupos sociais ou regiões em detrimento do todo. As políticas regulatórias, que são mais visíveis ao público, envolvendo burocracia, políticos e grupos de interesse que regulam o comportamento da sociedade. As políticas redistributivas, são aquelas que atinge maior número de pessoas e impõe perdas concretas e no curto prazo para certos grupos sociais e ganhos incertos e futuro para outros; são, em geral, as políticas sociais universais, por exemplo, o sistema tributário e o sistema previdenciário. Finalmente, as políticas constitutivas, que lidam com procedimentos.

Há necessidade de destacar que essa tipologia leva-nos ao argumento apresentado por Lemieux (2001), segundo o qual à primeira vista, algumas políticas públicas parecem focar mais na quantidade de recursos do que em sua distribuição, o que pode fomentar o nível de desigualdades sociais.

\subsection{Políticas Públicas de Emprego}

Atualmente existem uma diversidade de políticas públicas voltadas para a redução do desemprego e para a elevação da produtividade (BARROS $E$ CARVALHO, 2002). As políticas passivas fornecem suporte de renda para pessoas desempregadas, por exemplo, seguro-desemprego e o Subsídio para Candidato a Emprego, no entanto, as políticas ativas, tais como a assistência e serviços de emprego, programas de treinamento e provisão de emprego direto, destinam-se a ajudar os desempregados a voltar ao trabalho com novas competências (KELLY et al., 2011). No entanto, na prática, os governos há muito que se engajam em uma variedade de políticas ativas que intervêm diretamente no mercado de trabalho com o objetivo de gerar mais e melhores oportunidades de emprego para os trabalhadores (MACKENZIE, 2017).

O principal objetivo das políticas ativas de emprego é aumentar as oportunidades de emprego para aqueles que o procuram, como também, melhorar a adequação entre os postos de trabalho (vagas) e os trabalhadores (ou seja, os desempregados). Desta forma, as políticas ativas podem contribuir para 0 crescimento do emprego e do Produto Interno Bruto e reduzir o desemprego e a dependência de subsídios. As políticas ativas variam desde ofertas de formação institucionais e no local de trabalho acerca dos incentivos indiretos ao emprego (preservação do posto de trabalho, partilha do posto de trabalho e incentivos ao recrutamento) até à criação de emprego protegido e apoiado ou à oferta de incentivos para a criação direta de emprego (programas de interesse público) ou para o arranque de uma atividade (COMISSÃO EUROPEIA, 2017). Isso significa que as políticas ativas contribuem para assegurar que os desempregados regressam o 
mais rapidamente possível a uma situação de emprego e que esse emprego é o mais adequado possível.

As Políticas passivas envolvem os gastos com seguro-desemprego, auxíliodesemprego e programas de aposentadoria/reforma antecipada. Porém, essa diferenciação bem definida nem sempre se aplica a economias emergentes e em desenvolvimento onde os programas de apoio à renda tendem a privilegiar os grupos mais vulneráveis da população, sem uma condicionalidade estrita do mercado de trabalho (PIGNATTI E BELLE, 2018). Moçambique encontra-se nessa situação, pois, a lista dos grupos vulneráveis é grande, desde as Pessoas com Deficiência, idosos, vítimas de desastres naturais, vítimas da violência baseada no género, deslocados de ataques armados, as crianças órfãs, até as famílias afetadas diretamente pela COVID-19.

De acordo com Kelly et al. (2011), as principais estratégias para a implementação de políticas ativas de emprego são:

\section{Auxílio na procura de emprego, monitoramento e sanções}

Incluem uma variedade de medidas que visam aumentar a eficácia da procura de emprego. Exemplos de tais medidas incluem: aconselhamento, monitoramento, cursos de procura de emprego, orientação profissional, estabelecimento de planos de ação individuais, encaminhamento directo para empregos vagos e a imposição de sanções quando os candidatos a emprego não cumprem as atividades de procura de emprego exigidas para o recebimento dos benefícios dos subsídios de desemprego.

\section{Programas de treinamento}

O principal objetivo dos programas de treinamento é aumentar o capital humano dos candidatos a emprego e, portanto, suas perspetivas de emprego. Os programas de treinamento variam de acordo com o tipo de candidato a emprego. Por exemplo, alguns candidatos a emprego exigem treinamento básico de busca de emprego ou outras habilidades gerais (por exemplo, habilidades básicas de informática), enquanto outros realizam treinamento mais intensivo e específico para melhorar sua empregabilidade ou para garantir empregos de melhor qualidade. A formação tende a representar a maior parte dos gastos com medidas ativas de emprego; especificamente, esses programas precisam ser direcionados aos participantes, em escala relativamente pequena, e estabelecer vínculos fortes com os empregadores locais por meio da inclusão de um componente prático no programa de formação.

\section{Programas de criação de empregos no sector público}

A assistência na procura de emprego e o treinamento buscam principalmente influenciar o lado da oferta do mercado de trabalho, enquanto a criação direta de empregos no sector público e os incentivos à criação de empregos no sector privado procuram influenciar o lado da demanda. No sector público os programas de criação de empregos se concentram na criação de oportunidades públicas que produzem bens e serviços públicos. O principal objetivo deste tipo de programa é manter o desempregado à procura de emprego em contacto com o mercado de trabalho e, assim, evitar a erosão do seu capital humano durante o período de desemprego. No entanto, esses empregos muitas vezes não estão próximos do mercado de trabalho regular, visto que, tendem a ser temporários. 


\section{Programas de incentivos do sector privado}

O objetivo destes programas é criar incentivos que alterem o comportamento do empregador e/ou do trabalhador em relação ao emprego no sector privado. Por exemplo, os subsídios salariais no sector privado têm como objetivo encorajar os empregadores a criar novos empregos ou a manter os cargos existentes. Esses subsídios, que podem ser dados diretamente ao empregador ou empregado, tendem a ser por um período fixo de tempo e muitas vezes são direcionados a indivíduos mais desfavorecidos. Os incentivos ao início de atividades, que são fornecidos a indivíduos desempregados que desejam estabelecer seu próprio negócio, são outro tipo de programa de incentivo do sector privado.

Segundo Barros e Carvalho (2002), as principais políticas ativas de emprego e renda podem ser agrupadas em três tipos:

\section{Microcrédito}

O microcrédito é uma política ativa que visa reduzir o desemprego e elevar a produtividade do trabalho. Em termos do desemprego, ele é uma arma contra o seu componente estrutural, na medida em que leva à expansão da produção e, consequentemente, a um aumento na demanda por trabalho. Este tipo não tem qualquer impacto sobre a qualificação dos trabalhadores e sobre a informação disponível. Em termos da busca por aumentos da produtividade, o microcrédito é um instrumento útil para a melhoria na qualidade dos postos de trabalho, pois, pode aumentar o investimento em capital físico e induzir à incorporação de novas tecnologias.

2. Treinamento profissional

O treinamento profissional é também uma política ativa que visa combater tanto o desemprego, como a baixa produtividade da força de trabalho. Ele é vital para a redução do desemprego, na medida em que, ao expandir a qualificação de alguns trabalhadores, dá a eles acesso a uma série de postos de trabalho, aos quais não teriam acesso sem treinamento adicional.

3. Intermediação de mão-de-obra

Esta política visa combater as imperfeições de informação no mercado de trabalho, na medida em que a intermediação aumenta a informação disponível a trabalhadores e firmas, ela reduz o período de desemprego, não tem impacto direto sobre a qualificação dos trabalhadores, nem sobre a quantidade e a qualidade dos postos de trabalho disponíveis.

Para efeitos dessa pesquisa, entendemos as políticas ativas de emprego como sendo aquelas que visam facilitar a entrada ou regresso dos jovens e adultos ao mercado de trabalho, envolvendo a formação profissional, iniciativas de emprego promovidas pelos governos locais, estágios profissionais, empreendedorismo, a intermediação laboral e projetos de inserção dos jovens no mercado.

\subsection{Pessoa com Deficiência}

A deficiência faz parte da condição humana. Quase todas as pessoas terão uma deficiência temporária ou permanente em algum momento de suas vidas, e aqueles que sobreviverem ao envelhecimento enfrentarão dificuldades cada vez maiores com a funcionalidade de seus corpos. A maioria das grandes famílias possui um familiar deficiente, e muitas pessoas não deficientes assumem a responsabilidade de prover suporte e cuidar de parentes e amigos com deficiências (ORGANIZAÇÃO MUNDIAL DA SAÚDE, 2011). De acordo com Resolução oㅡ 20/99 de 23 de Junho que aprovou a Política para a Pessoa Portadora de Deficiência, 
"qualquer redução ou perda de capacidade normal para um ser humano resultante de um impedimento, significa deficiência.

A Pessoa com Deficiência é aquela que possui alteração parcial ou completa de um ou mais segmentos de seu corpo, acarretando comprometimento da função física, auditiva, visual ou intelectual e que em função de contingências histórias, sociais e espaciais, essa alteração poderá resultar em perda da autonomia para a pessoa, trazer problemas de discriminação social e dificultar a inserção social das pessoas com deficiência (CARVALHO-FREITAS, 2009). Portanto, a falta de conhecimento por parte dos administradores, da capacidade de trabalho da pessoa com deficiência dificulta a inclusão dos indivíduos com deficiência no mercado de trabalho (CARREIRA, 2013). Os estudos sobre a inclusão das pessoas com deficiência $(P c D)$ vêm, nos últimos anos, sendo consolidados com o foco direcionado à inclusão no mercado de trabalho, uma vez que esse tema tem se configurado como uma questão atual, polêmica, e de grande importância para as organizações, por se referir a um grupo relevante socialmente (SILVA E HELAL, 2017). Assim sendo, este grupo tem clamado por protecção social e inclusão, na medida em que, integram a população vulnerável de países como Moçambique.

\section{RESULTADOS}

\subsection{Quadro Legal e Institucional sobre a Inclusão das Pessoas com Deficiência em Moçambique}

Iniciativas nacionais e internacionais tais como as Regras Padrões sobre Equiparação de Oportunidades para Pessoas com Deficiência, das Nações Unidas, têm incorporado os direitos humanos das pessoas com deficiência, culminando em 2006 com a adoção da Convenção das Nações Unidas sobre os Direitos das Pessoas com Deficiência (CDPD) (Organização Mundial da Saúde, 2011).

Em Moçambique, tem um quadro legal e institucional que preserva os direitos das PcD. A Lei Fundamental do Estado moçambicano, a Constituição da República de Moçambique (2004 e 2018), no artigo 37 define os deveres e direitos das PcD, nos seguintes termos:

Os cidadãos portadores de deficiência gozam plenamente dos direitos consignados na Constituição e estão sujeitos aos mesmos deveres com ressalva do exercício ou cumprimento daqueles para os quais, em razão da deficiência, se encontrem incapacitados.

O texto constitucional, atualiza de forma protetora a necessidade de tratamento não diferenciado da PcD previsto pela Resolução no 20/99 de 23 de Junho que aprovou a primeira Política para a Pessoa Portadora de Deficiência defendia que "por força do texto constitucional, o cidadão portador de deficiência, como regra geral, tem as mesmas obrigações, deveres e direitos dos demais compatriotas." Esta política pública já incorpora elementos que promovem a equidade e cidadania, dois valores fundamentais dum Estado de Direito e Democrático.

Portanto, o governo Moçambique observando a necessidade de acelerar a intervenção para a resolução dos problemas das $\mathrm{PCD}$, operacionalizou no intervalo entre 2009 a 2013, uma política pública para garantir o cumprimento dos direitos e respeito pelos deveres dos deficientes no aparelho do Estado, que se designou de Estratégia da Pessoa Portadora de Deficiência na Função Pública.

Para reforçar a proteção social das Pessoas com Deficiência, o Estado moçambicano apostou no Plano Nacional para a Área da Deficiência - PNAD II 
(2012 - 2019). Na perceção de Meneses (2014), para promoção de uma plena participação, igualdade e empoderamento das pessoas portadoras de deficiência; bem como assegurar a igualdade de direitos e oportunidades destas pessoas, este instrumento de governação foi elaborado.

O governo de Moçambique aprovou também uma política pública para o segundo mandato do Presidente Filipe Jacinto Nyusi, nomeadamente, a Estratégia Nacional de Segurança Social Básica (ENSSB II) 2016-2024 que visa materializar o Programa Quinquenal do Governo, através da implementação de ações que concorrem para a redução da pobreza e da vulnerabilidade, assegurando que os resultados do crescimento da economia moçambicana beneficiem a todos os cidadãos, sobretudo os que vivem em situação de pobreza e de vulnerabilidade.

Para efeitos de harmonização das políticas públicas de apoio as $\mathrm{PcD}$ e proteção social dos grupos mais carenciados, através do Decreto 47/2018 de 6 de Agosto, do Conselho de Ministros, foram revistos e atualizados todos os Programas de Assistência Social de forma incremental, desde a designação e os seus objetivos, passando a ser:

1. Programa Subsídio Social Básico (PSSB): consiste na realização de transferências monetárias regulares mensais por tempo indeterminado, para reforçar o nível de consumo, autonomia e resiliência dos Agregados Familiares (AFs) que vivem em situação de pobreza e vulnerabilidade, bem como a melhoria da nutrição das crianças;

2. Programa Apoio Social Direto (PASD): consiste em transferências sociais pontuais ou prolongadas por tempo determinado, em forma de apoio multiforme para fazer face a choques e situações diversificadas de emergência que afetam indivíduos ou AFs em situação de pobreza e vulnerabilidade;

3. Programa de Atendimento em Unidades Sociais (PAUS): consiste num conjunto de intervenções orientada para o acolhimento permanente ou temporária a pessoas desamparadas, ou em risco no ambiente familiar ou comunitário;

4. Programa Ação Social Produtiva (PASP): consiste em transferências monetárias mediante a realização de atividades produtivas para (AFs) expostos a insegurança alimentar crónica, agravada pelos choques e riscos estruturais e impactos das mudanças ambientais e/ou choques económicos; e

5. Programa Ação Social Produtiva (PASP): consiste em transferências monetárias mediante a realização de atividades produtivas para AFs expostos a insegurança alimentar crónica, agravada pelos choques e riscos estruturais e impactos das mudanças ambientais e/ou choques económicos.

Observando para as finalidades e os problemas que essas políticas públicas pretendem resolver, elas incorporam subsídios diretos as pessoas vulneráveis e não o reforço de capacidades para a reinserção dos grupos vulneráveis no mercado de emprego para a sua autossuficiência. Ou melhor, o governo moçambicano investe mais em políticas públicas passivas para suprir a lacuna da exclusão das $\operatorname{PcD}$ e de outros grupos vulneráveis no mercado, através de subvenções financeiras revestidas em forma de subsídio. 


\subsection{Inclusão das Pessoas com Deficiência no Mercado de Emprego: Alternativas e Desafios}

No âmbito das políticas passivas de emprego, o Centro de Integridade Pública (CIP, 2020), demostrou num dos seus estudos que uma das preocupações está associado ao facto de alguns responsáveis pela inscrição de beneficiários destas políticas públicas (geralmente os chefes de quarteirão) inscrevem-se a si próprios e aos seus familiares ou conhecidos, os quais geralmente não fazem parte do grupo dos mais vulneráveis, deixando assim de lado as pessoas que efetivamente deveriam fazer parte destas listas, num contexto em que existem pessoas que preenchem os requisitos necessários para receber os subsídios mas ficam em listas de espera por muitos anos. Por tanto, um dos entrevistados do CIP (2020), portador de deficiência e reside em Matutuine, testemunhou o alto nível de exclusão das PcD nas políticas passivas, dado que, se encontra em lista de espera há cerca de três anos e nunca foi chamado.

Os dados do IV Recenseamento Geral da População e Habitação de 2017, evidenciou que existiam em Moçambique cerca de 736038 Pessoas com Deficiência, num universo de 26899105 de habitantes, representando uma percentagem de 2,7, um número que justifica a implementação de políticas públicas que promovem ações afirmativas e a empregabilidade deste grupo específico. Há necessidade de evidenciar que as estatísticas oficiais distribuem também a quantidade das PcD no país em função do tipo de deficiência, como demonstrado na tabela 1.

Tabela 1-Distribuição das PcD pelo tipo de deficiência Tipo de Deficiência $\quad$ Frequência Percentagem

\begin{tabular}{lrr} 
& \multicolumn{2}{c}{ (\%) } \\
\hline Cego & 58021 & 7,9 \\
\hline Surdo/Mudo & 68326 & 9,3 \\
\hline Braço (s)/amputado (s)/ atrofiado (s) & 55670 & 7,6 \\
\hline Perna (s)/amputada (s)/atrofiada (s) & 115918 & 15,7 \\
\hline Paralisia & 44875 & 6,1 \\
\hline Mental & 49565 & 6,7 \\
\hline Dificuldade para ver mesmo usando óculos & 81072 & 11 \\
\hline Dificuldade para ouvir mesmo usando aparelho & 35803 & 4,9 \\
auditivo & & \\
\hline Dificuldade de memória ou de concentração & 30173 & 4,1 \\
\hline Dificuldade de locomoção (andar) & 105529 & 14,3 \\
\hline Outra & 91086 & 12,4 \\
\hline Total & 736038 & 100 \\
\hline
\end{tabular}

Fonte: Elaborado pelo autor através dos dados do IV Censo Geral (INE, 2017).

Se observarmos para o sexo das PcD, 372061 correspondente a 51 por cento eram Homens e 355559 equivalente a 49 por cento eram Mulheres (Conferir o gráfico 1).

\section{Gráfico 1- Percentagem das Pessoas com Deficiência em função do sexo}




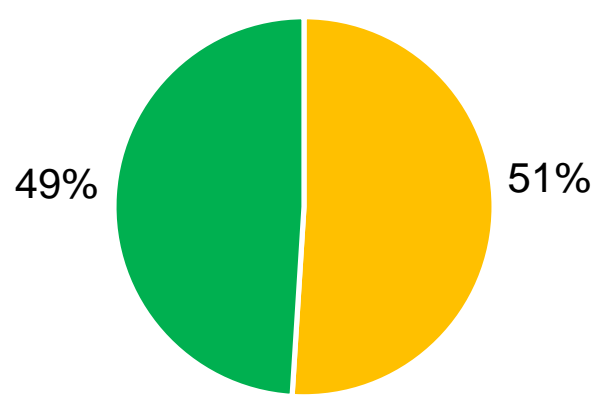

HOMENS - MULHERES

Fonte: IV Recenseamento Geral da População e Habitação (INE, 2017).

Em relação as deficiências adquiridas por meio de acidentes de trabalho o quadro 2 demostra que as deficiências mais frequentes são: perna (s) amputada (s) ou atrofiada (s) (25,6 por cento), braço (s) amputado (s) ou atrofiado (s) (23,8 por cento) e Dificuldade de locomoção (andar) (17,7 por cento). (Conferir a tabela 2).

Tabela 2-Pessoas com Deficiência causada por Acidentes de Trabalho

\begin{tabular}{lcr}
\hline \multicolumn{1}{c}{ Tipo de Deficiência } & $\begin{array}{c}\text { Número de PcD } \\
\text { Causadas por } \\
\text { Acidentes de } \\
\text { Trabalho }\end{array}$ & $\begin{array}{c}\text { Percentagem } \\
\text { (\%) }\end{array}$ \\
\hline Cego & 1561 & 4,9 \\
\hline Surdo/mudo & 457 & 1,4 \\
\hline Braço (s)/amputado (s)/ atrofiado (s) & 7521 & 23,8 \\
\hline Perna (s)/amputada (s)/atrofiada (s) & 8073 & 25,6 \\
\hline Paralisia & 1001 & 3,2 \\
\hline Mental & 312 & 1,0 \\
\hline Dificuldade para ver mesmo usando óculos & 3045 & 1,1 \\
\hline Dificuldade para ouvir mesmo usando & 338 & 0,9 \\
aparelho auditivo & & 17,7 \\
\hline Dificuldade de memória ou de concentração & 278 & 10,7 \\
\hline Dificuldade de locomoção (andar) & & 100 \\
\hline Outra & 5583 & \\
\hline TOTAL & 3373 & 31542 \\
\hline
\end{tabular}

Fonte: IV Recenseamento Geral da População e Habitação (INE, 2017). 
Constata-se que muitas dessas deficiências acabam limitando o acesso da PcD ao mercado de emprego e agudizando comportamentos de descriminação e descrença nas capacidades atuais, depois de sofrer um acidente.

Com base nas nossas entrevistas efetuadas a cerca de seis pessoas portadoras de alguma deficiência, foi possível verificar que há predominância de políticas de emprego passivas do que as ativas, pois, as entidades governamentais como é o caso do Instituto Nacional de Ação Social, acabam atribuindo um subsídio ínfimo para custear o seu autossustento, apesar das PcD em alguns casos demostrarem-se com vontade de desempenharem atividades remuneratórias que qualquer membro da sociedade pode exercer. Portanto, esta exclusão das PcD por alegada invalidez no mercado de trabalho moçambicano denota a existência de práticas discriminatórias nas organizações moçambicanas, tanto as governamentais do nível central e local, como as empresas privadas, apesar das PcD demostrarem na prática que têm competências (Conhecimentos, Habilidades e Atitudes) que os demais. Pois vejamos, a $E_{1}$ respondeu o seguinte na entrevista:

"Eu nasci muda e a primeira dificuldade que enfrentei foi a exclusão no sistema de educação, porque as nossas escolas primárias, secundárias e até universidades não estão preparadas para 0 ensino de Pessoas com Necessidades Especiais. E acabamos sendo excluídos pela sociedade, porque as empresas e as pessoas reparam-nos como inválidos e ninguém quer aprender a língua de sinais que nós usamos. Atualmente, trabalho no associativismo e numa organização que defende os interesses das PcD, pelo facto das empresas privadas e organizações públicas não estarem preparadas para receber-nos. Somos excluídos de muitas oportunidades de emprego."

$A E_{2}$ respondeu o seguinte, na entrevista cedida:

"Sou deficiente a muito tempo, sou surdo-mudo, mas tenho muitos amigos e conhecidos que tem habilidades de cozinha e outras que podiam trabalhar em restaurantes, mas, porque foram rejeitados continuam nas ruas a pedir esmola para sobreviver, visto que, alguns não recebem o subsídio do INAS e os que recebem não chega para nada."

Podemos entender que as PcD têm vontade de contribuir ativamente no desenvolvimento da sociedade, por conseguinte, a ação de atribuir um subsídio de assistência social a este grupo de cidadãos, uma política de emprego passiva, constitui uma fonte que reduz o engajamento e fortalecimento destes. No entanto, a subvenção financeira atribuída a cada deficiente não é suficiente para minimizar a situação de vulnerabilidade social na qual estão sujeitas, pois, o custo de vida tende a aumentar e o salário mínimo que é a base de cálculo desses subsídios não têm aumentado na proporção do crescimento da inflação (índice do preço do consumidor). (verificar a tabela 3 ). 
Tabela 3-Evolução do Subsídio do INAS para as PcD versus Inflação e Salário Mínimo ITEM ANOS

\begin{tabular}{|c|c|c|c|c|c|}
\hline & $\begin{array}{c}\text { № de Membros } \\
\text { do Agregado } \\
\text { Familiar } \\
\text { beneficiário }\end{array}$ & 2018 & 2019 & 2020 & 2021 \\
\hline \multirow{5}{*}{$\begin{array}{c}\text { Subsídio } \\
\text { do INAS } \\
\text { para } \\
\text { PcD } \\
\text { (Em } \\
\text { meticais) }\end{array}$} & 1 pessoa & $540 \mathrm{MT}$ & $540 \mathrm{MT}$ & $540 \mathrm{MT}$ & $540 \mathrm{MT}$ \\
\hline & 2 pessoas & $640 \mathrm{MT}$ & $640 \mathrm{MT}$ & $640 \mathrm{MT}$ & $640 \mathrm{MT}$ \\
\hline & 3 pessoas & $740 \mathrm{MT}$ & $740 \mathrm{MT}$ & $740 \mathrm{MT}$ & $740 \mathrm{MT}$ \\
\hline & 4 pessoas & $840 \mathrm{MT}$ & $840 \mathrm{MT}$ & $840 \mathrm{MT}$ & $840 \mathrm{MT}$ \\
\hline & 5 pessoas & $1.000 \mathrm{MT}$ & $1.000 \mathrm{MT}$ & $1.000 \mathrm{MT}$ & $1.000 \mathrm{MT}$ \\
\hline \multicolumn{2}{|c|}{$\begin{array}{c}\text { Inflação Acumulada } \\
(\%)\end{array}$} & 3,52 & 3,50 & 3,52 & 3,07 \\
\hline \multicolumn{2}{|c|}{$\begin{array}{c}\text { Salário Mínimo } \\
\text { (Em meticais, administração } \\
\text { pública) }\end{array}$} & 4255,00 & 4467,75 & 4467,75 & 4467,75 \\
\hline
\end{tabular}

Fonte: INE (2021), UNICEF (2018) e ABCC (2019).

Um dado relevante que merece realce é que as PcD que são assistidas nas políticas públicas sob implementação do Instituto Nacional de Ação Social (INAS) são aquelas que obedecem aos critérios de elegibilidade deste órgão, através dos instrumentos definidos no artigo 24 do Decreto 47/2018 de 6 de Agosto, do Conselho de Ministros, a destacar:

- Ter um Cartão de assistência social para o acesso aos subsídios;

- Ter a Caderneta de Assistência Social, na qual se regista o tipo de apoio concedido aos beneficiários dos diferentes programas.

Nestes moldes, fica evidente que o primeiro desafio é aceder aos programas que atribuem estes subsídios, mas também, inverter a abordagem governamental de investir em políticas passivas em todos os seus programas de proteção social às PcD para as ativas. Conforme refere Mackenzie (2017) e a Comissão Europeia (2017), as políticas ativas podem gerar mais e melhores oportunidades de emprego, para aqueles que procuram melhorar a adequação entre os postos de trabalho (vagas) e os trabalhadores (ou seja, os desempregados), dessa forma contribuir para o crescimento do emprego, do Produto Interno Bruto, reduzir o desemprego e a dependência de subsídios.

Se compararmos o total das PcD (736 038) apresentados pelo IV Censo de 2017 e os beneficiários assistidos em 2018 segundo o Plano Economico Social-PES e UNICEF, cerca de 567 290, é possível constatar que muitos deficientes não são cobertos pelas políticas públicas de assistência social. Porém, o número de beneficiários deficientes reduz ainda mais se levarmos em consideração que dos 567290 assistidos pelo INAS, não incluem apenas as PcD, mas igualmente, crianças, idosos e outros grupos vulneráveis sem capacidade de renda e subsistência.

O segundo desafio está na monitoria, fiscalização e inspeção que o ministério que tutela a área de emprego e trabalho deve fazer regularmente aos 
empregadores, para evitar a exclusão de PcD no acesso ao mercado, pelo facto de terem alguma deficiência. Assim sendo, é aceitável que haja um investimento considerável nas políticas ativas, para efeito de preparar esse grupo específico com ferramentas e competências relevantes para competirem em pé de igualdade com outros candidatos em busca das melhores oportunidades de emprego ou autoemprego.

A monitoria e fiscalização tem amparo legal na Lei do Trabalho moçambicana, Lei $n^{\circ}$ 23/2007 de 1 de Agosto, no artigo 28, onde protege o trabalhador deficiente nos seguintes termos:

1. O empregador deve promover a adoção de medidas adequadas para que o trabalhador portador de deficiência ou portador de doença crónica goze dos mesmos direitos e obedeça aos mesmos deveres dos demais trabalhadores no que respeita ao acesso ao emprego, formação e promoção profissionais, bem como às condições de trabalho adequadas ao exercício de atividade socialmente útil, tendo em conta as especificidades inerentes a sua capacidade de trabalho reduzida;

2. O Estado, em coordenação com as associações sindicais e de empregadores, bem como com as organizações representativas de pessoas portadoras de deficiência, estimula e apoia, no quadro da promoção do emprego, tendo em conta os meios e recursos disponíveis, as ações tendentes a proporcionar a reconversão profissional e a integração em postos de trabalho adequados à capacidade residual de trabalhadores com deficiência;

3. Podem ser estabelecidas, por lei ou instrumento de regulamentação coletiva de trabalho, medidas especiais de proteção do trabalhador portador de deficiência, nomeadamente as relativas à promoção e acesso ao emprego e às condições de prestação da atividade adequada às suas aptidões, exceto se essas medidas implicarem encargos desproporcionados para o empregador.

Nestes moldes, algumas alternativas para a inclusão das PcD só podem prosperar com uma reforma institucional ou legal, nas regras de candidatura para ingresso no aparelho do Estado e no sector privado, ou melhor, o Estatuto Geral dos Funcionários e Agentes do Estado e a Lei do Trabalho devem incluir cotas para admissão de $\mathrm{PcD}$, por exemplo, estabelecer que para todos concursos no processo de recrutamento de mão-de-obra dez a quinze por cento devem ser ocupadas por $\mathrm{PcD}$, onde nos anúncios de candidatura deve estar inclusa uma nota que diz: incentivamos a candidatura de PcD com o perfil da vaga; não só mas também, há necessidade de retirar do texto legal qualquer excerto que pode autorizar 0 empregador implicitamente a excluir o candidato por razão de ter alguma deficiência.

O terceiro desafio está associado a educação especial para sociedade moçambicana entender o básico da língua de sinais, o que facilitará a inclusão das PCD em todos sectores da sociedade moçambicana. Em termos de alternativas, a inclusão nos curricula do alfabeto da língua de sinais na disciplina de português a partir da quinta classe e a promoção de campanhas de divulgação das regras de leitura e escrita. 


\section{Conclusão}

A inclusão das Pessoas com Deficiência nas políticas de emprego em Moçambique acontecem por meio de medidas passivas de atribuição de subsídios de apoio através duma subvenção financeira mensal que varia entre os 540 a 1000 meticais, dependendo do tamanho do agregado familiar. Esses valores são muito insignificantes para agregados familiares maiores, pois, devido as taxas altas de inflação, aos salários mínimos que estão a dois anos sem incremento e pelo facto dos valores ainda não refletirem o custo de vida alto no país, alguns deficientes ainda continuam a depender de esmolas e a boa vontade dos vizinhos.

E as políticas públicas de emprego que assistem as $\mathrm{PcD}$ em Moçambique, que encontram amparo legal na Constituição da República do país, nomeadamente, Programa Subsídio Social Básico (PSSB), Programa Apoio Social Direto (PASD), Programa de Atendimento em Unidades Sociais (PAUS), Programa Ação Social Produtiva (PASP), Programa Ação Social Produtiva (PASP) são implementadas pelo Instituto Nacional de Ação Social, portanto, para além das lacunas existentes na gestão dos subsídios, os critérios de seleção por dependerem da boa vontade do chefe do quarteirão e do técnico do INAS são excludentes para as $\mathrm{PcD}$, visto que parte considerável dos deficientes ainda não beneficiam do mesmo. Nestes moldes, os cursos de formação profissional e programas de treinamentos direcionados para as $\mathrm{PcD}$ em Moçambique para áreas como informática, restauração, contabilidade, procurement, gestão de contratos, gestão de pequenos negócios, secretariado e gestão de recursos humanos, seriam boas alternativas para prepará-los para desafiarem o mercado de trabalho.

Concluindo, as políticas públicas de emprego em Moçambique são predominantemente passivas, no entanto, dos subsídios alocados desde 2018 até 2021 não sofreram nenhum incremento, apesar do comportamento da inflação demostrar o aumento do alto custo de vida. No entanto, elas devem continuar, desde que sejam mais inclusivas e os empregadores precisarão ser socializados a participar nos programas que revitalizem as políticas ativas para este grupo vulnerável.

\section{Agradecimentos}

Agradeço a Organização Não-Governamental de defesa dos direitos das Pessoas com Deficiência e media inclusiva em Moçambique TV SURDO, pelo apoio prestado na recolha de dados.

\section{Referências}

BARROS, Ricardo Paes de, CARVALHO, Mirela. Políticas activas de emprego e renda. MERCADO DE TRABALHO: conjuntura e análise. [S. I.], 2002.

CARREIRA, D.. Integração da pessoa deficiente no mercado de trabalho. 1997

CARVALHO-FREITAS, M. N. Inserção e Gestão do Trabalho de Pessoas com Deficiência: um Estudo de Caso. Revista de Administração Contemporânea, v. 13, p. 121-138, 2009.

CIP. COVID-19: Recursos alocados para protecção social podem não chegar na totalidade aos beneficiários- Os mecanismos de controlo do INAS não têm sido 
eficientes para evitar desvios de fundos durante a distribuição de subsídios. Maputo, edição n 26, 2020.

COMISSÃO EUROPEIA. Políticas Activas do Mercado de Trabalho. 2017. Disponível em: https://ec.europa.eu/info/sites/default/files/file import/europeansemester thematic-factsheet active-labour-market-policies pt.pdf, acesso em $10 \mathrm{de}$ jun. de 2021.

CONSTITUIÇÃO DA REPÚBLICA DE MOÇAMBIQUE (2004).

CONSTITUIÇÃO DA REPÚBLICA DE MOÇAMBIQUE (2018) (actualizada).

DYE, Thomas. R..Understanding public policy. 15 ed. New York: Pearson, 2017.

KELLY, E., MCGUINNESS, S., O'CONNELL, P. J.. What Can Active Labour Market Policies Do? RENEW AL SERIES. PAPER 1, 2011.

KELLY, Tom. Middle East and North Africa jobs crisis 'may import terror into Europe". 2016, Daily Mail, 26 May. Disponível em: http://www.dailymail.co.uk/news/article-3611803/Middle-East-NorthAfrica-jobs-crisisimport-terror-Europe.html, acesso em: 11 de Jun. de 2021.

LEMIEUX, Vincent. Décentralisation, politiques publiques et relations de pouvoir. Québec: Presses de l'Université de Montréal, 2001.

LEMIEUX, Vincent. Les politiques publiques et les alliances d'acteurs. l'Université du Québec à Chicoutimi, 1994. Disponível em: https://docplayer.fr/3219394-Les-politiques-publiques-et-les-alliances-d-acteurs.html, acesso em: 13 de Jun. de 2021.

MACKENZIE, David. How Effective Are Active Labor Market Policies in Developing Countries? A Critical Review of Recent Evidence. Policy Research Working Paper 8011. World Bank Group, 2017. Disponível em: https://openknowledge.worldbank.org/handle/10986/26352, acesso em: 13 de Jun. de 2021.

MENESES, Rita Catarina Paiva Castro Patrício. Protecção Social e Deficiência: o caso de Moçambique. Porto, 2014. Dissertação (Mestrado Estudos Africanos Educação e Desenvolvimento)-Universidade do Porto.

MOHAMMED, Omar. Africa has the World's fastest-growing labor force but needs jobs growth to catch up. Quartz Africa, November 13, 2015. Disponivel em: https://qz.com/547929/africa-has-the-worldsfastest-growing-labor-force-but-needs-

jobs-growth-to-catch-up/. Acesso em: 15 de Jun. de 2021

ORGANIZAÇÃO MUNDIAL DA SAÚDE (2011). Relatório mundial sobre a deficiência. São Paulo, 2011.

PIGNATTI, Clemente, BELLE, Eva Van (2018). Better together: Active and passive labour market policies in developed and developing economies. Research Department Working Paper No. 37, International Labour Organization-ILO, 2018.

Resolução n 20/99 de 23 de Junho, Política para a Pessoa Portadora de Deficiência.

SILVA, Alice Gerlane Cardoso da, HELAL, Diogo Henrique. A Inclusão de Pessoas com Deficiência no Mercado de Trabalho Brasileiro Perspectivas e Desafios. Rev. FSA, Teresina, v. 14, n. 5, 2017.

SITOE, Eduardo, LUMBELA, Sélcia. Módulo de Planificação, Análise e Avaliação de Políticas Públicas. Maputo, 2013.

THEODOULOU, Stella, CAHN, Matthew. Public policy: the essential readings. 2 Ed. New Jersey: Prentice Hall, 2012.

TRINDADE, Igor dos Santos Alves. Pessoas com deficiências físicas no mercado de trabalho moçambicano: estudo exploratório. Lisboa, 2020, Dissertação (Mestrado em Ciências do Trabalho e Relações Laborais)-ISCTE.

UNICEF Moçambique. Informe Orçamental 2018-Acção Social. Maputo, 2018. 
WORLD BANK. Unlocking the Employment Potential in the Middle East and North Africa: Toward a New Social Contract. World Bank, Washington D.C., 2004, disponível em: http://documents.worldbank.org/curated/en/343121468753030506/pdf/288150PAPE R0Unlocking0employment.p. acesso em: 23 de Jun. de 2021. 